JOURNAL OF ARCHITECUTRE AND URBANISM RESEARCH

Available online http://ojs.uma.ac.id/index.php/jaur

\title{
REDESAIN SMAN 3 PADANG DENGAN PENDEKATAN SUSTAINABLE ARCHITECTURE
}

\author{
Muhammad Razki Adrell'1, Pedia Aldy², Gun Faisal ${ }^{3}$ \\ 1)Mahasiswa Prodi Arsitektur Fakultas Teknik Universitas Negri Riau, Indonesia \\ 2, 3) Dosen Prodi Arsitektur Fakultas Teknik Universitas Negri Riau, Indonesia
}

Diterima: Januari 2021; Disetujui: Februari 2021; Dipublikasi: April 2021

*Corresponding author: razkiadrell@gmail.com

\begin{abstract}
Abstrak
Penyediaan lingkungan belajar yang baik di sekolah dapat meningkatkan kesehatan dan produktivitas pelajar. SMAN 3 Padang merupakan salah satu institusi pendidikan yang masih kurang dalam memperhatikan lingkungan belajar, yang membutuhkan penyelesaian desain untuk memberikan solusi ke depan. Dengan menggunakan pendekatan sustainable architecture mampu menghadirkan rancangan sustainable school dengan lingkungan belajar yang lebih baik dan berdampak positif pada lingkungan sekolah. Melalui analogi dari konsep "belajar seperti di bawah naungan pepohonan" dan ditransformasikan dengan pendekatan sustainable architecture. Redesain SMAN 3 Padang dapat memberikan lingkungan belajar yang berkelanjutan di sekolah untuk meningkatkan produktivitas siswa dan kemampuan siswa di masa depan, terutama prestasi sekolah.
\end{abstract}

Kata Kunci : $\mathrm{SMAN}_{3}$ Padang, sustainable architecture, belajar seperti di bawah naungan pepohonan

\begin{abstract}
Providing a good learning environment at school can improve student health and productivity. SMAN 3 Padang is one of the educational institutions that still lacks attention to the learning environment, which requires completion of the design to provide solutions going forward. Using a sustainable architecture approach is able to present a sustainable school design with a better learning environment and a positive impact on the school environment. Through the analogy of the concept of "learning as under the auspices of trees" and transformed with a sustainable architecture approach. The redesign of SMAN 3 Padang can provide a sustainable learning environment in schools to improve student productivity and student abilities in the future, especially school performance.
\end{abstract}

Keywords: $\mathrm{SMAN}_{3}$ Padang, sustainable architecture, learning as under the auspices of trees

How to Cite : Adrell M.R, Pedia A, Gun F (2021). Redesain SMAN 3 Padang dengan Pendekatan Suistanable Architecture, JAUR (Journal of Architecture and Urbanism Research). 4 (2): 114-123 


\section{PENDAHULUAN}

SMAN 3 Padang merupakan salah satu sekolah favorit di Kota Padang namun, sebagai lembaga pendidikan belum memperhatikan secara khusus lingkungan belajar terutama dalam segi desain. Beberapa permasalahan desain yang dapat identifikasi berupa tatanan massa bangunan yang berhimpit, penghawaan yang kurang baik, penataan lahan yang kurang efektif, perencanaan zona parkir yang tidak tepat serta sirkulasi kendaraan juga bermasalah. Keadaan ini dikarenakan SMAN 3 Padang tidak memiliki pedoman rencana pengembangan sekolah kedepannya yang menyebakan kekurangan dalam segi desain (Elmizen, 2019).

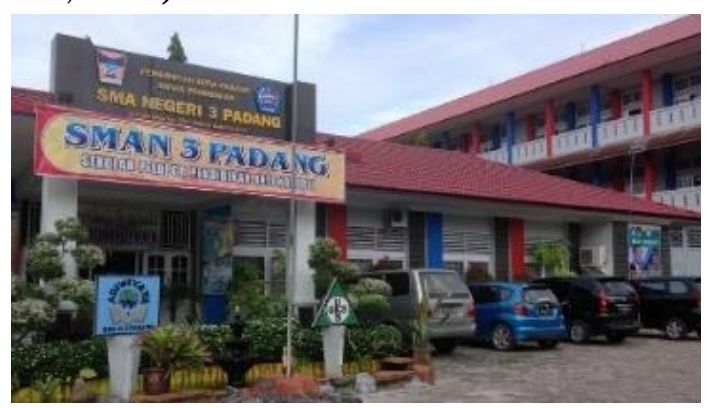

Gambar 1. SMAN 3 Padang

Sumber: www.sman3padang.sch.id, 2019

Desain suatu sekolah memiliki pengaruh terhadap kegiatan pengguna didalamnya terutama dalam pembelajaran. Hal ini berpengaruh dengan kondisi eksisting sekolah yang ada sekarang, peringkat SMAN 3 Padang berdasarkan hasil UN SMA se-Kota Padang antara tahun 2015-2019 mengalami penurunan (Puspendik Kemendikbud, 2019). Permasalahan lainnya adalah tidak sebandingnya daya tampung dengan sarana fisik sekolah (Dinas Pendidikan Provinsi Sumatera Barat, 2015).

Berdasarkan kondisi diatas SMAN 3 Padang telah merencanakan rehabilitasi sarana dan prasarana sekolah dalam rangka meningkatkan kualitas pendidikan yang tertuang dalam Rencana Kerja Jangka Menengah (RKJM) SMA Negeri 3 Padang tahun 2019-2023. RKJM ini menyebutkan masih banyak sarana sekolah yang masih belum memenuhi standar maupun yang mengalami kerusakan.

Sekolah yang mendukung nilai keberlanjutan dalam desain, konstruksi dan operasional merupakan lingkungan belajar yang lebih baik (Gelfand, 2010). Sedangkan Olson (2003) menyatakan sekolah yang berkelanjutan menyediakan lingkungan yang terang, sehat, nyaman yang kondusif untuk belajar dan meningkatkan prestasi siswa sekaligus menghemat pengeluaran, energi, dan sumber daya. Berbagai manfaat tersebut membuktikan bahwa sekolah dengan desain berkelanjutan memiliki dampak positif terhadap lingkungan sekolah terutama dalam aspek pembelajaran.

Sustainable architecture dipilih sebagai bentuk penyelesaian desain dalam menerapkan sekolah berkelanjutan pada SMAN 3 Padang dikarenakan sebelum melakukan perancangan melihat karakter dan kondisi setempat baik lingkungan maupun budaya. Hal ini dapat meningkatkan produktivitas belajar dan kemampuan siswa melalui sebuah desain yang lebih baik.

Redesain merupakan solusi yang tepat dilakukan dikarenakan kondisi eksisting sekolah memiliki kekurangan dalam segi desain sehingga hanya perlu didesain ulang dan tanpa perlu dibongkar secara keseluruhan dengan mempertahankan beberapa elemen eksisting sesuai kebutuhan. Redesain SMAN 3 Padang diharapkan dapat menyediakan lingkungan belajar yang lebih baik, untuk meningkatkan produktivitas belajar dan kemampuan siswa demi meningkatkan prestasi sekolah kedepannya. 
Andriani (2015) menyatakan arsitektur berkelanjutan mempersentasikan sikap dalam melihat karakter dan kondisi setempat baik lingkungan dan budaya sebelum melakukan perancangan yang kaya akan keunikan lokal dan ramah lingkungan meskipun dibalut dengan teknologi tinggi.

Tabel 1. Prinsip Sustainable Architecture

\begin{tabular}{|c|c|}
\hline The Principles & The Application \\
\hline Ecology Strategy & $\begin{array}{l}\text { Menyediakan vegetasi di } \\
\text { lokasi atau taman vertical } \\
\text { Menawarkan taman atap }\end{array}$ \\
\hline Energy Strategy & $\begin{array}{l}\text { Menggunakan sistem } \\
\text { pendingin pasif } \\
\text { Menggunakan bahan } \\
\text { konstruksi lokal } \\
\text { Menggunakan teknologi } \\
\text { sensorik } \\
\begin{array}{l}\text { Menggunakan sumber } \\
\text { energi terbarukan }\end{array}\end{array}$ \\
\hline Waste & $\begin{array}{l}\text { Pengolahan limbah cair } \\
\text { dan padat menjadi } \\
\text { sumber energi } \\
\text { Menggunakan } \\
\text { recyle dan reuse }\end{array}$ \\
\hline Material & $\begin{array}{l}\text { Reuse } \\
\text { Recycle } \\
\text { Menggunakan bahan } \\
\text { yang diproduksi cepat } \\
\text { seperti bambu } \\
\text { Menggunakan bahan } \\
\text { lokal } \\
\text { Menggunakan sistem } \\
\text { konstruksi prefabrikasi } \\
\text { dengan sistem modular } \\
\text { Pemanfaatan ulang } \\
\text { Penggunaan kembali } \\
\text { adaptif }\end{array}$ \\
\hline $\begin{array}{l}\text { Community in } \\
\text { Neighboorhood }\end{array}$ & $\begin{array}{l}\text { Rasa hormat dan } \\
\text { kepedulian terhadap } \\
\text { masyarakat } \\
\text { Pemperkuat kepedulian } \\
\text { komunitas } \\
\text { Eko-urbanisme } \\
\text { Saling membantu satu } \\
\text { sama lain }\end{array}$ \\
\hline
\end{tabular}

\begin{tabular}{ll}
\hline Economy & Penyediaan lowongan \\
Strategy & pekerjaan \\
\hline Culture & Revitalisasi bangunan \\
Invention & tradisional cara \\
& Melestarikan pada \\
& bangunan yang ada pada \\
& bangunan konvensional \\
& Menggunakan tenaga \\
& kerja lokal \\
& Melestarikan budaya \\
\hline Operational & Pengelolaan terpadu \\
Management & untuk pengolahan air \\
& limbah \\
\hline
\end{tabular}

Sumber: Andriani, 2020 (diolah penulis)

\section{METODE PENELITIAN}

Pada Redesain SMAN 3 Padang ini memiliki strategi perancangan dengan tahapan yang dimulai dengan survei instansi, pemahaman teori, analisis eksisting, analisis fungsional, analisis sistem bangunan, analisis tapak, analisis tampilan fisik bangunan dan analisis tema. Selanjutnya merumuskan konsep redesain untuk mencapai tahap redesain dan mendapatkan hasil redesain.

Metode yang digunakan untuk mengumpulkan data terbagi menjadi dua, data primer yaitu pengamatan langsung terhadap obyek berupa survei intansi, dokumentasi, observasi serta wawancara. Sedangkan data sekunder merupakan studi literatur yang berkaitan seperti jurnal, buku, skripsi, tesis atau disertasi maupun media.

Lokasi Perancangan berada di SMAN 3 Padang berada di Jalan Gajah Mada No. 11, Kelurahan SMAN 3 Padang berada di Jalan Gajah Mada No. 11, Kelurahan Gunung Pangilun, Kecamatan Padang Utara, Kota Padang, Provinsi Sumatera Barat. 


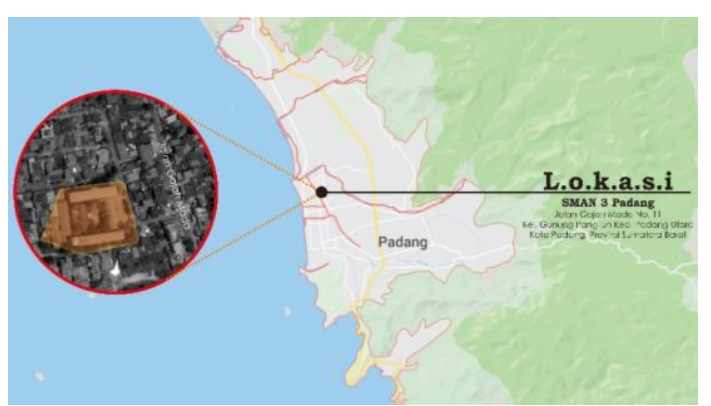

Gambar 2. Lokasi SMAN 3 Padang Sumber: Google Maps, 2020

Berdasarkan analisis perhitungan besaran ruang SMAN 3 Padang dapat dilihat pada tabel berikut:

Tabel 2. Kebutuhan Ruang

\begin{tabular}{llll}
\hline \multirow{2}{*}{ No. } & Nama Fasilitas & \multicolumn{2}{l}{ Luas $\mathbf{( m}^{\mathbf{}} \mathbf{)}$} \\
\cline { 3 - 4 } $\mathbf{1}$ & $\begin{array}{l}\text { Pelaksanaan } \\
\text { Pendidikan }\end{array}$ & 2965 & 4097 \\
\hline $\mathbf{2}$ & $\begin{array}{l}\text { Pelaksanaan } \\
\text { Hubungan }\end{array}$ & 1723 & 3045 \\
\hline $\mathbf{3}$ & $\begin{array}{l}\text { Pelaksanaan } \\
\text { Administrasi }\end{array}$ & 482 & 403 \\
\hline $\mathbf{4}$ & $\begin{array}{l}\text { Pendukung } \\
\text { dan Servis }\end{array}$ & 1983 & 2191 \\
\hline Total & 7153 & 9736 \\
\hline Ruang Luar & 5186,4 & 5775 \\
\hline
\end{tabular}

Konsep yang digunakan dinamakan "belajar seperti dibawah naungan pepohonan". Konsep tersebut selaras dengan makna sustainable architecture, dimana respon terhadap melihat karakter dan kondisi lingkungan sekitar sebagai bentuk kepedulian terhadap lingkungan yang mempertimbangkan aspek kedepannya. Konsep ini terinspirasi karena pohon merupakan tempat yang sangat nyaman untuk berteduh dibawahnya sambil melakukan aktivitas.

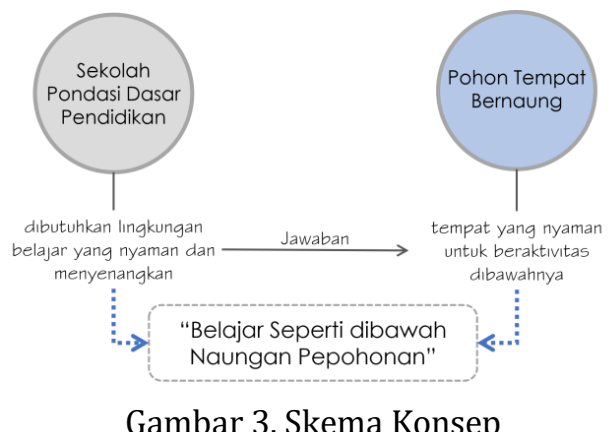

Untuk menciptakan suasana belajar yang nyaman seperti dibawah pohon. Terdapat dua unsur pada pohon yang menimbulkan kenyamanan untuk bernaung dibawahnya, yaitu peneduh dan keterbukaan. Peneduh berfungsi untuk menangkal panas sinar matahari dan keterbukaan untuk membiarkan udara dan cahaya masuk dari samping (natural lights dan natural ventilation). Unsur nantinya diaplikasikan pada bangunan untuk menciptakan suasana belajar yang nyaman seperti berada dibawah pohon.

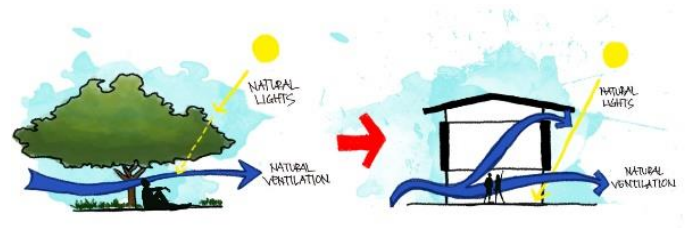

Gambar 4. Unsur "Belajar di Bawah Naungan Pohon"

Konsep ini dijabarkan bagaimana suasana pepohonan yang saling berkaitan antara satu sama lain. Kaitan tersebut berupa green spaces sebagai pusat yang menghubungkan antar pohon disekelilingnya. Bentukan massa disesuaikan terhadap orientasi cahaya matahari dan arah angin yang dominan datang dari arah barat. 


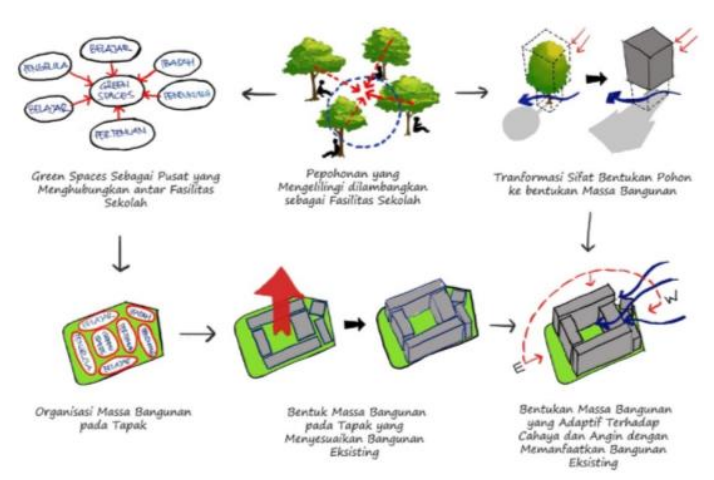

Gambar 5. Konsep Bentuk

Transformasi bentuk melalui hasil analisa eksisting lalu diolah berdasarkan konsep dan prinsip sustainable architecture.

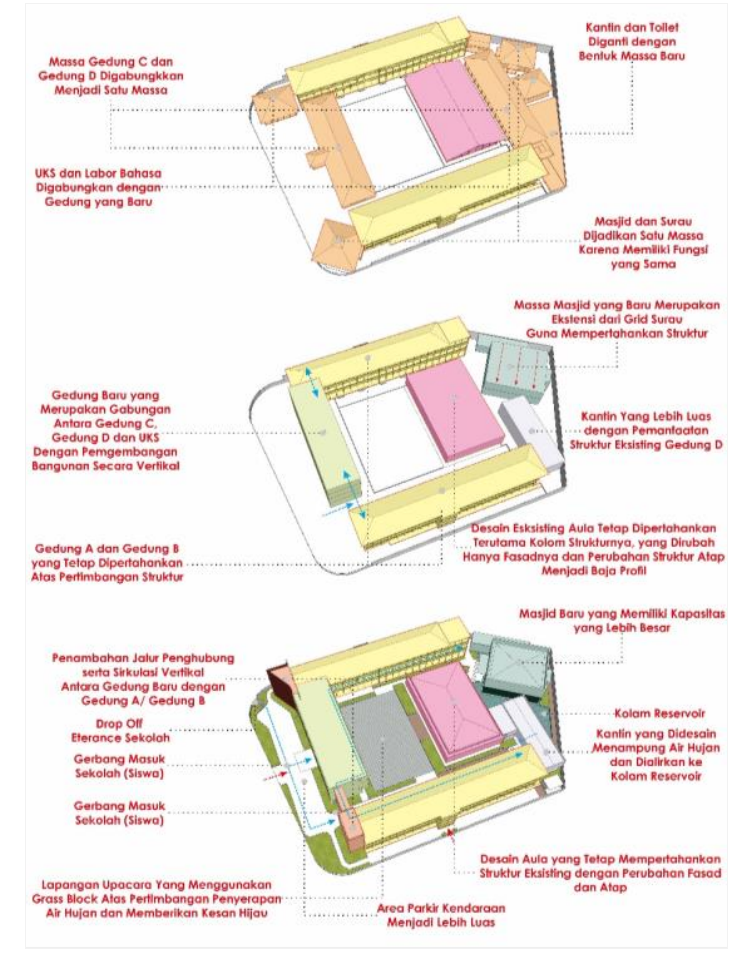

Gambar 6. Transformasi Bentuk

Penerapan konsep tapak berupa penyusunan massa bangunan yang mengelilingi tapak, mempertahankan beberapa bangunan eksisting serta pengembangan secara vertikal. Setiap massa bangunan ini menggambarkan sebagai pohon yang meneduhkan, mewadahi dan melindungi penggunanya sehingga susunan massa pada tapak dapat menggambarkan esensi susunan pepohonan.

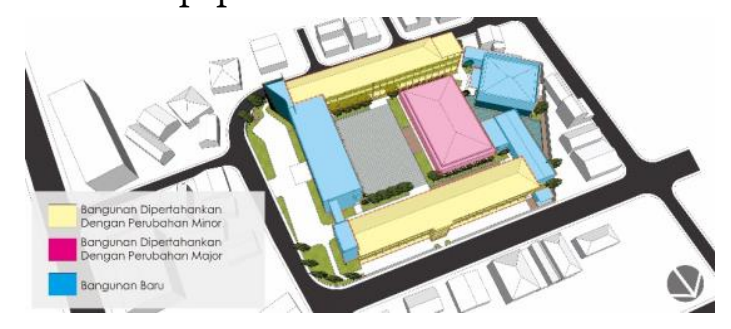

Gambar 7. Konsep Tapak

\section{Konsep Zoning}

Penzoningan memaksimalkan cahaya matahari dengan menyatukan beberapa ruang yang memiliki fungsi sejenis dalam satu bangunan agar lebih effiesien dari segi penataan lahan dan pencahayaan.

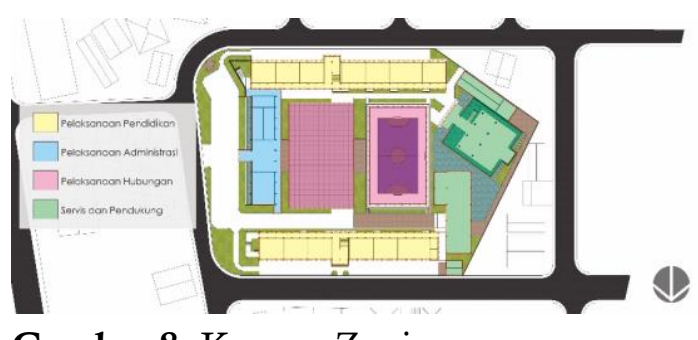

Gambar 8. Konsep Zoning

\section{Konsep Sirkulasi}

Sistem sirkulasi pada tapak dibedakan menjadi 4 jenis untuk menghindari potensi kepadatan kendaraan pada jam masuk dan pulang sekolah karena lokasi sekolah berada di area pemukiman yang dapat menggangu kenyamanan warga sekitar.

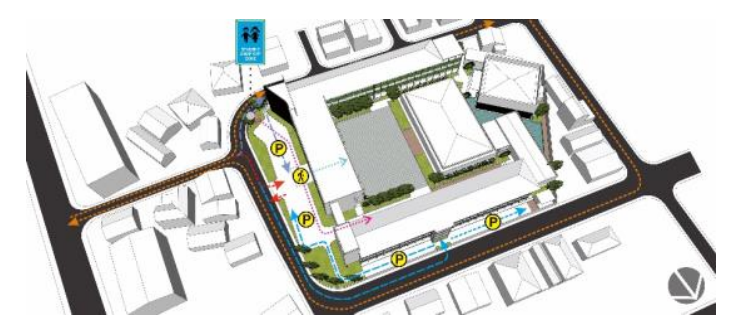

Gambar 9. Konsep Sirkulasi

\section{Konsep Vegetasi}

Vegetasi pada tapak berletak berdampingan dan mengelilingi bangunan untuk menciptakan citra visual dan termal 
terhadap pepohonan. Sehingga memunculkan ikatan dan keterkaitan antara pengguna, lansekap serta bangunan. Tujuan lainnya yaitu sebagai peredam visual antar bangunan yang berdekatan dikarenakan kondisi lahan yang sempit.

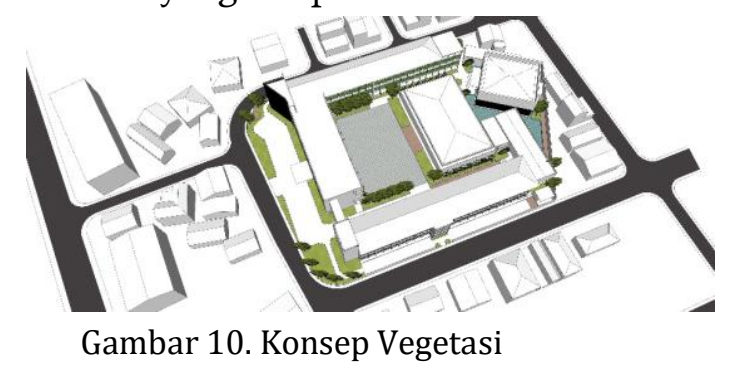

Konsep Interior memiliki konsep yang terbuka dan sederhana layaknya sebuah pohon. Desain furnitur yang praktis dan sederhana untuk mengakomodir akfitas didalamnya. Kemudahan sirkulasi udara dan pencahayaan merupakan poin penting dalam konsep interior sekolah.

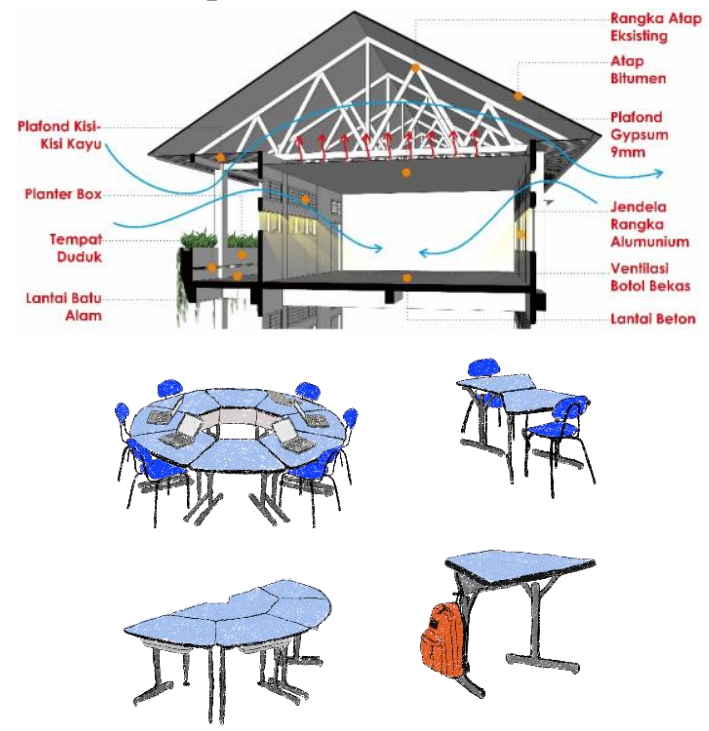

Gambar 11. Konsep Interior dan Furnitur Ruang Kelas

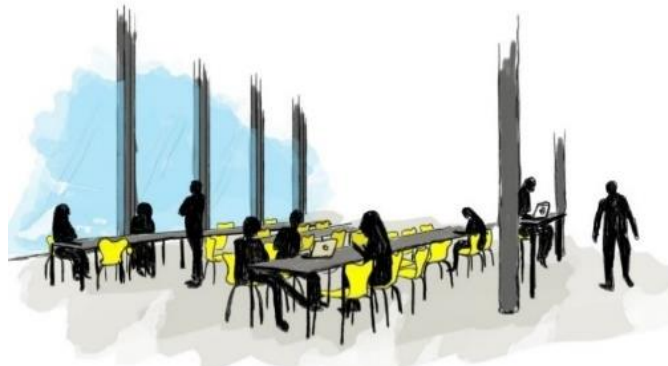

Gambar 12. Konsep Interior Perpustakaan

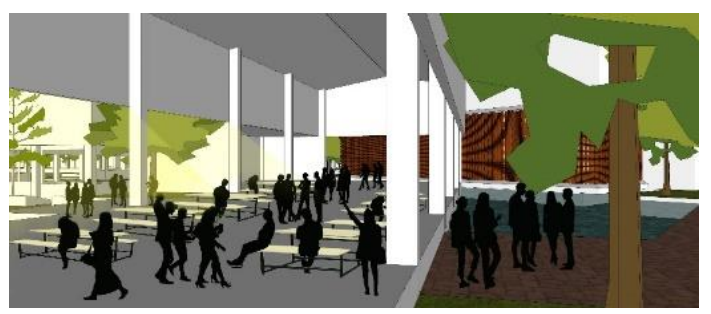

Gambar 13. Konsep Interior Kantin

Konsep Bentuk fasad memiliki pendekatan desain yang berbeda-beda pada setiap bangunan dikarenakan pepohonan memiliki bentuk, sifat dan jenis berbedabeda. Tujuannya memeberikan keanekaragaman citra visual namun tempat memiliki konsep yang selaras antar bangunan.

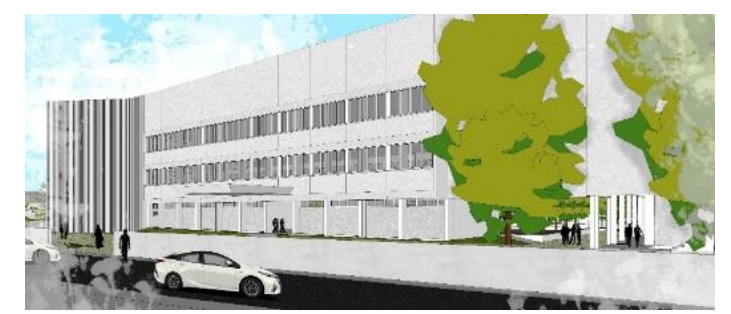

Gambar 14. Konsep Fasad Gedung Utama
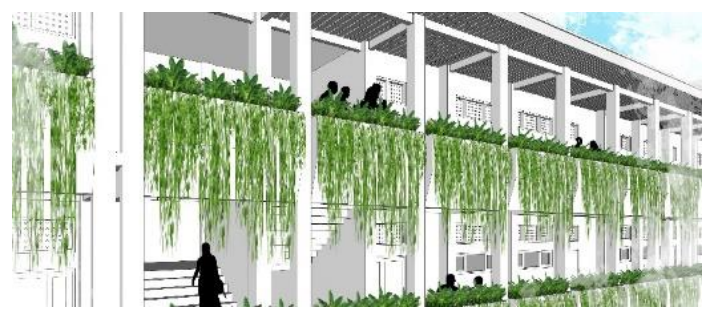

Gambar 15. Konsep Fasad Gedung A dan Gedung B 


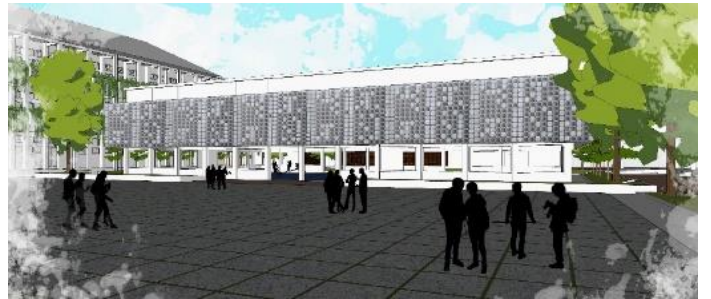

Gambar 16. Konsep Fasad Aula

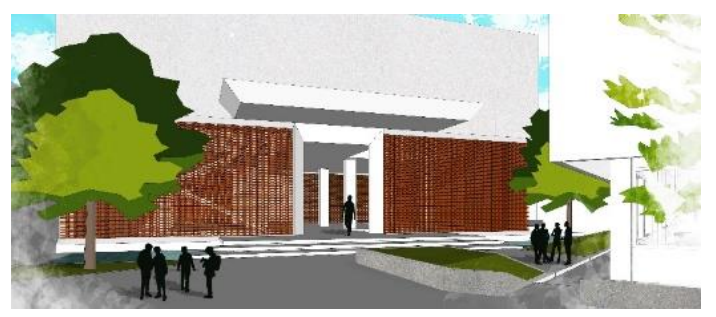

Gambar 17. Konsep Fasad Masjid

Penerapan Tema Pada Rancangan, prinsip sustainable architecture yang akan diterapkan pada Redesain SMAN 3 Padang:

Urban Ecology, Konsep massa yang mempertahankan beberapa bangunan sekolah eksisitng serta pembentukan massa bangunan baru secara vertikal agar memberikan efisiensi ruang di lahan yang sempit. Menciptakan ruang-ruang hijau pada bangunan sekolah seperti vertikal garden sebagai elemen pembentuk fasad yang juga berfungsi sebagai filter sinar matahari di siang hari. Hal ini bertujuan untuk menciptakan kenyamanan visual dan termal sehingga dapat menciptakaan lingkungan belajar yang asri dan ramah lingkungan.

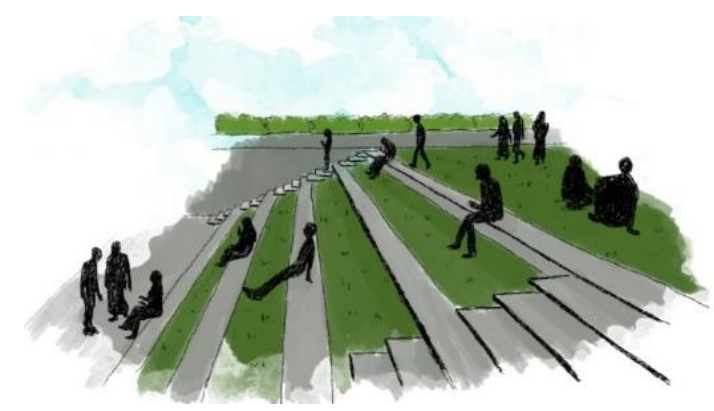

Gambar 18. Lansekap Ruang Outdoor

Energy Strategy, Memanfaatkan
solartubes dan lightshelves untuk
memaksimalkan pencahayaan alami
terutama pada ruang-ruang yang sulit
mendapatkan sinar matahari langsung.

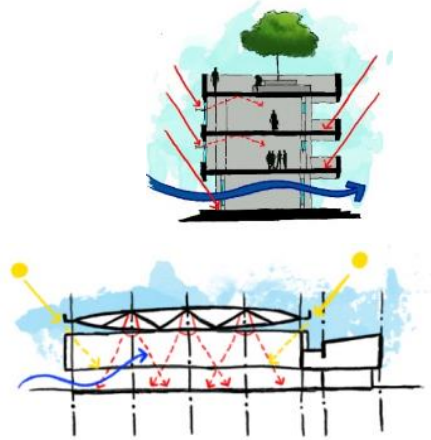

Gambar 19. Aplikasi Lightsleeves pada Gedung Baru dan Solartubes pada Aula

Massa bangunan yang bervolume lebih tinggi (Gedung Baru, Gedung A dan Gedung B) berada di sisi timur, utara dan selatan tapak atas pertimbangan pencahaayaan dan arah angin. Sedangkan pada sisi barat, terdapat massa bangunan yang bervolume rendah (Aula, Kantin dan Mesjid). Gunanya untuk memaksimalkan arah angin yang dominan datang dari sisi barat ke bangunan yang lebih tinggi.

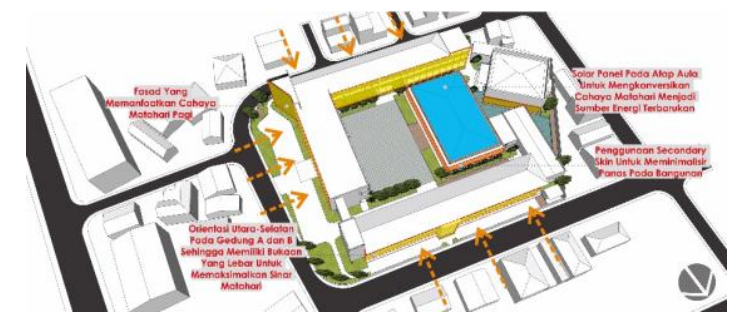

Gambar 20. Hasil Desain Pencahayaan

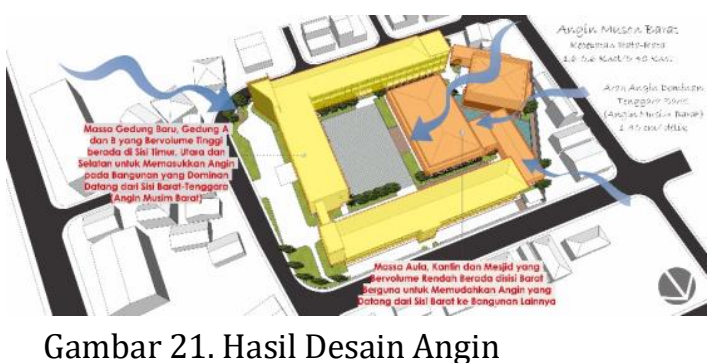

Gambar 21. Hasil Desain Angin 
Penggunaan sistem pemipaan tertutup pada bangunan untuk memaksimalkan tekanan air dalam mengurangi kerja pompa distribusi yang banyak membutuhkan energi.

Water, Konsep lansekap mempertimbangkan sistem penyerapan air, pengelolaan air serta vegetasi. Tidak lupa pula penggunaan sistem bio retensi pada lansekap.

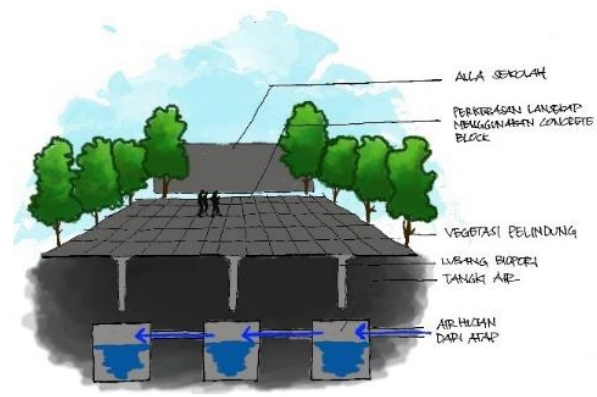

Gambar 22. Konsep Lansekap

Pengumpulan air hujan melalui atap untuk digunakan kembali. Air hujan yang ditampung dalam kolam reservoir yang dimanfaatkan sebagai elemen penyejuk, area rekreasi, irigasi, air toilet dan reservoir sistem kebakaran yang terdapat air mancur sebagai pendingin evaporatif.

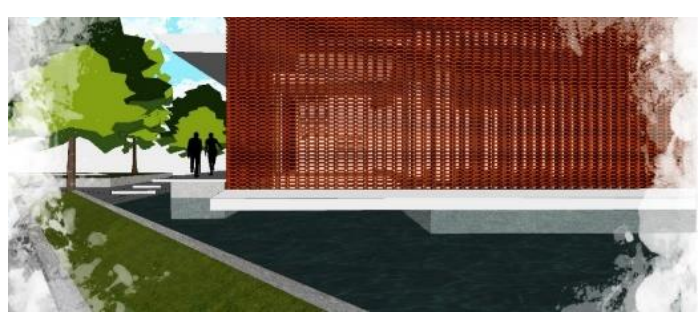

Gambar 23. Kolam Reservoir

Waste

Pemanfaatan kembali air pada bangunan melalui sistem air daur ulang. Serta terdapatnya bak pengolahan sampah untuk memilah sampah yang dapat didaur ulang, dikomposkan dan dibuang.

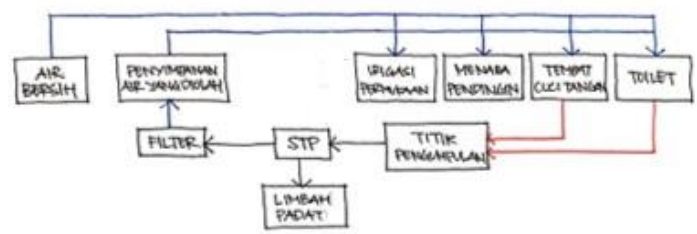

Gambar 24. Sistem Penggunaan Air Daur Ulang

Penggunaan material bekas pada bangunan melalui desain ventilasi yang memanfaatkan botol plastik bekas. Ventilasi ini berada pada Gedung A dan Gedung B yang merupakan gedung belajar, sehingga pada saat proses belajar-mengajar tidak memerlukan penghawaan buatan. Menggunakan ember cat pada fasad Aula sebagai bentuk reuse-recycle pada material bangunan.

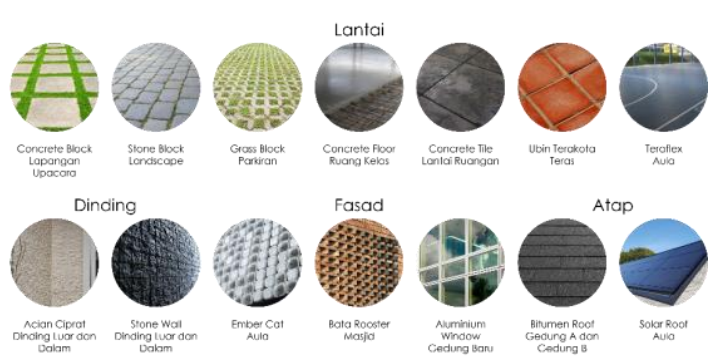

Gambar 25. Konsep Material

Community in Neighboorhosod, Pembatasan area parkir bagi seluruh warga sekolah untuk mengurangi penggunaan kendaraan bermotor. Penataan massa menyesuaian fungsi untuk memudahkan pencapaian. Mengatur pencapaian menuju sekolah yang memudahkan akses kendaraan dan pejalan kaki sehingga memberikan kenyamanan warga sekolah maupun lingkungan sekitar. 


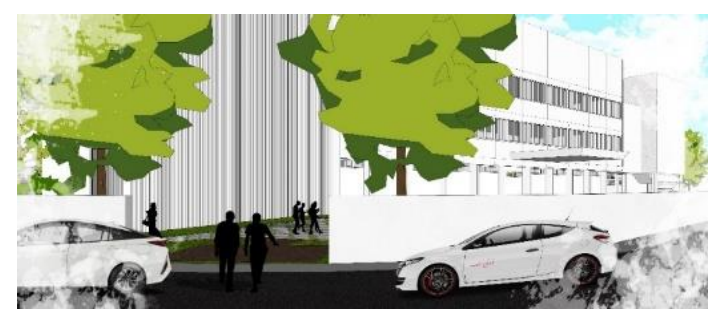

Gambar 26. Drop Off Zone

Penyediaan ruang terbuka hijau di lingkungan sekolah melalui taman, kolam reservoir, green house untuk menciptakaan kenyamanan visual, mendekatkan warga sekolah terhadap lingkungan, dan meningkatkan kesadaran lingkungan. Menciptakan ruang-ruang yang fleksibel seperti: ruang kelas menggunakan meja yang portable sehingga memudahkan proses diskusi maupun belajar kelompok, kantin yang dapat berfungsi sebagai ruang komunal, dan koridor sebagai area pertemuan informal.

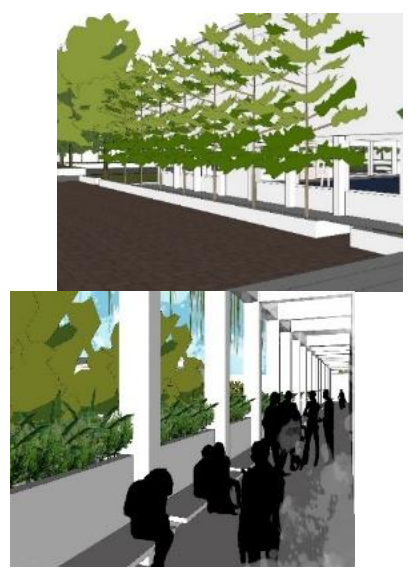

Gambar 27. Taman dan Koridor Ruang Kelas

Prinsip strategi ekomi yang diterapkan merupakan desain skala bangunan. Penerapaannya berupa penghematan penggunaan air dan listrik pada sekolah yang memiliki nilai penggunaan dan pembiayaan yang sangat besar melalui: (a) Pemanfaatan air hujan dan air limbah yang digunakan kembali untuk kebutuhan sehingga menghemat pemakaian air baru; (b) Penggunaan sistem pemipaan terutup untuk meringankan kerja pompa distribusi yang mengkonsumsi energi listrik; (c) Pengggunaan solar panel sebagai sumber energi listrik terbarukan dengan memperhantikan orientasi bangunan yang menghadap utara dan selatan terutama pada ruang belajar sehingga tidak memerlukan pencahayaan buatan; (d) Penggunaan zero electricity air cooler melalui botol plastik pada ventilasi ruang kelas yang berorientasikan arah angin sehingga tidak memerlukan penghawaan buatan; dan (e) Pemilihan material yang dapat digunakan dalam jangka panjang untuk menekan biaya perawatan bagunan.

Culture Invention, Hasil desain tidak merubah secara signifikan kegiatan, budaya maupun sistem sekolah yang ada. Hal bertujuan untuk mempertahankan bentuk sekolah negeri yang dibungkus lebih modern melalui pengembangan fasilitas yang lebih baik. Penggunaan sistem bangunan yang konvesional dan umum digunakan di Kota Padang sehinggga dapat memanfaatkan tenaga kerja lokal dengan tetap diiringi dengan penggunaan teknologi terbarukan melalui sistem prefabrikasi pada pengembangan Aula dan Gedung Baru, penggunaan struktur rigid dan seisimic bearing pada Gedung Baru atas pertimbangan gempa serta, aplikasi solar panel pada atap Aula sebagai sumber energi terbarukan.

Operational Management, Kemudahan teknis perawatan bangunan sekolah yang mempertimbangkan material dan sistem yang sederhana namun memiliki dampak efisiensi yang tinggi dalam penggunaannya. Sistem pengelolaan air hujan dan limbah yang mudah pengelolaannya sehingga tidak menimbulkan penambahan nilai cost yang berlebihan. Selain itu pemilahan sampah pada bak pengelolaan sampah untuk 
mempermudah sampah yang dapat didaur ulang dan tidak dapat daur ulang.

\section{KESIMPULAN}

Redesain SMAN 3 Padang menghasilkan rancangan sekolah dengan desain berkelanjutan memiliki banyak dampak positif terhadap lingkungan sekolah terutama dalam aspek pembelajaran. Desain tersebut dapat dicapai melalui sustainable architecture sebagai bentuk penyelesaian desain dalam bidang arsitektur. Langkahlangkah yang perlu dilakukan dalam Redesain SMAN 3 Padang dengan Pendekatan Sustainable Architecture, diantaranya (a) Untuk dapat menjawab permasalahan pada SMAN 3 Padang, dilakukan analisa eksisting yang kemudian hasil analisanya digunakan sebagai dasar dan acuan dalam melakukan redesain, (b) Analisa dilakukan berdasarkan penerapan 9 prinsip sustainable architecture yang nantinya diterapkan melalui konsep sehingga menghasilkan konsep redesain yang sesuai, (c) Konsep "belajar seperti di bawah naungan pepohonan" dan ditransformasikan dengan pendekatan sustainable architecture dan diaplikasikan pada massa bangunan, interior, dan tapak

\section{DAFTAR PUSTAKA}

[1] Andriani, Yanita Mila. 2015. Sustainable Architecture: Arsitektur Berkelanjutan. Penerbit Erlangga, Jakarta.

[2]Dinas Pendidikan Provinsi Sumatera Barat. 2015. RENSTRA 2016-2021 Dinas Pendidikan Provinsi Sumatera Barat.

[3]Elmizen. 2019. "Tentang SMAN 3 Padang". Hasil Wawancara Pribadi: 1 Oktober 2019, SMAN 3 Padang.

[4]Gelfand, Lisa dan Freed, Eric Corey. 2010. Sustainable School Architecture: Design for
Elementary and Secondary Schools. Jhon Wiley \& Sons, New Jersey.

[5]Olson, Stephen L. dan Kellum, Shana. 2003. The Impact of Sustainable Buildings on Educational Achievements in K-12 Schools. Leonardo Academy Inc., Wisconsin.

[6]Puspendik, Kementerian Pendidikan dan Kebudayaan (Online), (https://puspendik.kemendikbud.go.id, diakses 9 Desember 2019)

[7]SMAN 3 Padang, Dinas Pendidikan Provinsi Sumatera Barat (Online), (www.sman3padang.sch.id, diakses 11 Desember 2019).

[8]SMAN 3 Padang. 2019. Rencana Kerja Jangka Menengah (RKJM) SMAN 3 Padang Tahun Pelajaran 2019/2020-2022/202. 